\title{
Delivering the goods through the BBB
}

\section{By Tim Fulmer, Senior Writer}

Ohio researchers have developed a viral vector-based, CNS-targeted gene therapy that treated spinal muscular atrophy in mice after i.v. injection. ${ }^{1}$ The vector crossed the blood brain barrier (BBB) in nonhuman primates as well. The next step will be studies in other mammals to assess the safety of the approach and to optimize its therapeutic window.

Biotech companies already are pursuing a variety of strategies to treat spinal muscular atrophy (SMA) (see Table 1, "Selected products in development for spinal muscular atrophy"), an autosomal recessive disorder caused by abnormally low levels of the survival motor neuron (SMN) protein in the lower motor neurons. The condition leads to neurological dysfunction and muscle atrophy.

The cause of low SMN levels is a loss of or mutation in the survival of motor neuron 1 telomeric (SMN1) gene, one of two nearly identical

"Kaspar and colleagues report the first example of an AAV vector that is able to cross the primate blood brain barrier and deliver a gene to the CNS following injection into the systemic circulation."

- Pedro Lowenstein,

Cedars-Sinai Medical Center
Boosting SMN in the CNS is predicted to treat disease. Two basic strategies are in development to accomplish that.

One approach seeks to increase endogenous SMN by targeting the SMN2 gene and correcting its splicing defect ${ }^{3,4}$ or by preventing degradation of SMN after transcription (see Box 1, "Blocking degradation of SMN").

A second approach uses gene therapy vectors to deliver exogenous $\mathrm{SMN}$ to diseased neurons. Although at least one group is developing a strategy for direct CNS delivery of the SMN1 gene (see Box 2, "Direct delivery of SMN to the CNS"), systemic delivery of the vector would avoid the undesirable risks and side effects of invasive delivery into the CNS.

Brian Kaspar, associate professor of pediatrics at The Ohio State University and principal investigator at the Center for Gene Therapy Nationwide Children's Hospital, is pursuing systemic delivery.

Kaspar and his team already have shown that intravenously injected adeno-associated virus serotype 9 (AAV9) was able to cross the BBB and target the CNS in both neonatal and adult mice. ${ }^{5}$

The team's latest work shows that the AAV9 vector delivers the human SMN1 gene to CNS tissue and treats SMA in mouse models.

In transgenic neonatal SMA mice, injection of the AAV9-SMN construct into the facial vein led to increased levels of SMN in the brain, spinal cord and muscles compared with those in untreated controls.

Increased levels of SMN correlated with improved motor function: $90 \%$ of treated animals regained the ability to right themselves compared with $0 \%$ of untreated animals. Treated mice also survived longer and showed steadier weight gain than animals that were untreated or received an AAV9-GFP control vector.

To assess the potential clinical application of AAV9-based gene delivery, the researchers intravenously injected AAV9-GFP into a

Table 1. Selected products in development for spinal muscular atrophy.

Source: BCIQ: BioCentury Online Intelligence

\begin{tabular}{|c|c|c|c|}
\hline Company & Product & Product description & Status \\
\hline Trophos S.A. & Olesoxime (TRO19622) & $\begin{array}{l}\text { Small molecule with cholesterol-like structure } \\
\text { that interacts with the mitochondrial } \\
\text { permeability transition pore (MPTP) }\end{array}$ & Phase Ib complete \\
\hline California Stem Cell Inc. & Motorgraft & $\begin{array}{l}\text { Stem cell-derived motor neuron replacement } \\
\text { product }\end{array}$ & Preclinical; start Phase I in 2010 \\
\hline $\begin{array}{l}\text { Isis Pharmaceuticals Inc. } \\
\text { (NASDAQ:ISIS) }\end{array}$ & ISIS-SMNRx & $\begin{array}{l}\text { Antisense oligonucleotide modulating the } \\
\text { splicing of pre-mRNA of survival of motor } \\
\text { neuron } 2 \text { centromeric (SMN2; SMNC) gene }\end{array}$ & Preclinical \\
\hline Genzyme Corp. (NASDAQ:GENZ) & $\begin{array}{l}\text { Adeno-associated virus serotype } 8 \\
\text { (AAV8)-survival motor neuron (SMN) }\end{array}$ & $\begin{array}{l}\text { Survival of motor neuron } 1 \text { telomeric (SMN1) } \\
\text { gene delivered using an AAV8 vector }\end{array}$ & Preclinical \\
\hline Paratek Pharmaceuticals Inc. & PTK-SMA1 & Tetracycline derivative & Preclinical \\
\hline Repligen Corp. (NASDAQ:RGEN) & $\begin{array}{l}\text { Decapping enzyme scavenger (DCPS) } \\
\text { inhibitor }\end{array}$ & DCPS inhibitor & Preclinical \\
\hline
\end{tabular}




\section{Box 1. Blocking degradation of SMN.}

Spinal muscular atrophy (SMA), an often fatal degenerative disease of the motor neurons, is caused by abnormally low levels of the survival motor neuron (SMN) protein.

In an article published in Genes \& Development, a University of Pennsylvania School of Medicine research group led by Gideon Dreyfuss described a proteasome-mediated degradation mechanism that may be responsible for the low levels of SMN. ${ }^{6}$ The researchers believe blocking that degradation pathway could be a new approach to increasing cellular levels of SMN and treating SMA.

Dreyfuss is professor of biochemistry and biophysics at the school and is an investigator at the Howard Hughes Medical Institute.

A cell culture reporter assay initially identified a small portion of the amino acid sequence of SMN that was responsible for destabilizing the protein.
Suspecting that the destabilizing sequence was in fact a degradation signal or 'degron' that targeted the SMN protein to the proteasome, the researchers treated the cells with proteasome inhibitors and found that the half-life of SMN was increased. Site-directed mutagenesis then confirmed that the degron sequence was required for the SMN to be targeted to the proteasome.

Dreyfuss told SciBX that he is now interested in using high throughput screening to identify compounds that interfere with the degron and prevent SMN from being shuttled to the proteasome.

"Keeping in mind that proteasome inhibitors may be too toxic in this therapeutic context, we are hoping to target factors upstream of the proteasome that are responsible for recognizing the degron of the SMN protein and flagging it for proteasome-mediated degradation," he said.
Dreyfuss noted that he and colleagues have previously reported that SMN deficiency causes widespread defects in gene splicing pathways in tissues throughout the SMA mouse model, not only in motor neurons. ${ }^{7}$ He believes that those defects could alter the function of cells surrounding motor neurons, contributing to their dysfunction and degeneration in SMA.

For that reason, Dreyfuss thinks that even an efficacious CNS-targeting gene therapy such as that outlined by Kaspar and his team "may not replace the need for other therapeutic strategies that correct SMN levels also in tissues outside the CNS."

The degron-targeting strategy and the cell culture assays used in the Genes \& Development paper are patented and available for licensing from the University of Pennsylvania Center for Technology Transfer, according to Dreyfuss. $\quad-T F$ healthy male cynomolgus macaque one day after birth.

Postmortem examination of the monkey's spinal cord revealed high GFP expression within the dorsal root ganglia and motor neurons, showing that AAV9 was able to cross the postnatal $\mathrm{BBB}$ and deliver a gene to the primate CNS. The findings were reported in Nature Biotechnology.

Although injection of AAV-based gene therapies directly into the primate CNS has been reported by other researchers, "Kaspar and colleagues report the first example of an $\mathrm{AAV}$ vector that is able to cross the primate blood brain barrier and deliver a gene to the CNS following injection into the systemic circulation," said Pedro Lowenstein, professor of medicine and pharmacology and director of the Board of Governors Gene Therapeutics Research Institute at Cedars-Sinai Medical Center and the University of California, Los Angeles.

\section{Safe and timely delivery}

Lowenstein told SciBX that an important next step is to determine the ideal time window for administering the AAV9-SMN construct to attain the best results in SMA patients.

In the Nature Biotechnology paper, Kaspar and his team explored the therapeutic window in mice. Timeline experiments showed that i.v. injection of AAV9-SMN at 1 or 2 days after birth completely rescued the defect in the SMA mice, whereas injection at day 5 led to more modest increases in survival. Mice injected at day 10 survived

\section{Box 2. Direct delivery of SMN to the CNS.}

One approach to treating spinal muscular atrophy (SMA) is to harness gene therapy vectors to deliver exogenous survival motor neuron (SMN) to diseased neurons directly.

Researchers at Genzyme Corp. have published in The Journal of Clinical Investigation a strategy to deliver the SMN1 gene directly into the mouse CNS using an adeno-associated virus serotype 8 (AAV8) vector. ${ }^{8}$

In transgenic SMA mouse models, injection of the AAV8-SMN construct into the cerebral lateral ventricles and the upper lumbar spinal cord led to widespread expression of SMN throughout the spinal cord.

Treated animals showed increased skeletal muscle function, which translated into improvements on several behavior tests of coordination and locomotion. The gene therapy also improved survival, with treated animals living 50 days but untreated controls only 15 days.
Marco Passini, corresponding author on the $\mathrm{JCl}$ paper and a principal scientist at Genzyme, told SciBX that confining delivery to the CNS would potentially make it possible to use lower doses of gene therapy than would be required for systemic delivery. CNS delivery also might avoid unwanted immune responses that might limit the ability of the vector to cross the blood brain barrier.

Passini acknowledged that SMN deficiency may give rise to secondary disease phenotypes in cardiac and gastrointestinal tissue. However, Genzyme's strategy is focused at this point on enhancing SMN in motor neurons because that is "the main driver of disease," he said.

Passini and colleagues are testing more AAV serotypes for their ability to deliver and express SMN in the CNS of "more complex preclinical models," he said. $-T F$ 


\section{ANALYSIS}

\section{TARGETS \& MECHANISMS}

no longer than animals injected with the AAV9-GFP control vector.

According to co-principal investigator Arthur Burghes, the team now wants "to define and expand the therapeutic window for AAV9SMN delivery in larger species such as pigs and primates." Burghes is associate professor of molecular genetics at Ohio State.

Kaspar added that tests in those animals also will be important to establish the safety and nonimmunogenicity of the AAV9-SMN construct.

Nationwide Children's Hospital has applied for provisional patents covering the AAV9 delivery strategy and the SMA findings, and that IP is available for licensing, Kaspar told SciBX.

Fulmer, T. SciBX 2(3); doi:10.1038/scibx.2010.329

Published online March 18, 2010

\section{REFERENCES}

1. Foust, K. et al. Nat. Biotechnol.; published online Feb. 28, 2010; doi:10.1038/nbt.1610

Contact: Brian Kaspar, The Ohio State University, Columbus, Ohio e-mail: brian.kaspar@nationwidechildrens.org
2. Burghes, A. \& Beattie, C. Nat. Rev. Neurosci. 10, 597-609 (2009)

3. Martz, L. SciBX 2(26); doi:10.1038/scibx.2009.1030

4. Lou, K.-J. SciBX 2(47); doi:10.1038/scibx.2009.1717

5. Foust, K. et al. Nat. Biotechnol. 27, 59-65 (2009)

6. Cho, S. \& Dreyfuss, G. Genes Dev.; published online March 1, 2010; doi:10.1101/gad.1884910

Contact: Gideon Dreyfuss, University of Pennsylvania School of Medicine, Philadelphia, $\mathrm{Pa}$.

e-mail: gdreyfuss@hhmi.upenn.edu

7. Zhang, Z. et al. Cell 133, 585-600 (2008)

8. Passini, M. et al. J. Clin. Invest.; published online March 15, 2010; doi:10.1172/JCl41615

Contact: Marco Passini, Genzyme Corp., Framingham, Mass. e-mail: marco.passini@genzyme.com

\section{COMPANIES \& INSTITUTIONS MENTIONED}

Cedars-Sinai Medical Center, Los Angeles, Calif.

Genzyme Corp. (NASDAQ:GENZ), Cambridge, Mass.

Howard Hughes Medical Institute, Chevy Chase, Md.

Nationwide Children's Hospital, Columbus, Ohio

The Ohio State University, Columbus, Ohio

University of California, Los Angeles, Calif.

University of Pennsylvania School of Medicine, Philadelphia, $\mathrm{Pa}$ 